\title{
Retrograde Endovascular Approach for Treating Unruptured Basilar Apex Aneurysms: Two Case Reports and Review of Literature
}

\section{Acesso endovascular retrógrado no tratamento de aneurismas não rotos do ápice basilar: relato de dois casos e revisão da literatura}

\author{
Marcus Alexandre Rotta ${ }^{1} \quad$ Guilherme M. Dias ${ }^{1} \quad$ André Luiz Rezende ${ }^{1} \quad$ Felix H. Pahl ${ }^{1}$ \\ Matheus Fernandes Oliveira ${ }^{1}$ José Marcus Rotta ${ }^{1}$ \\ 1 Department of Neurosurgery, Hospital do Servidor Público Estadual \\ de São Paulo, IAMSPE, São Paulo, São Paulo, Brazil \\ Address for correspondence Matheus Fernandes Oliveira, MD, \\ Department of Neurosurgery, IAMSPE, Av. Loefgreen 700, Apto 103, \\ Vila Mariana, São Paulo, São Paulo, Brazil, 04040-000 \\ Arq Bras Neurocir 2017;36:128-132. \\ (e-mail: mafernoliv@yahoo.com.br).
}

\begin{abstract}
Background Treatment of target lesions when parent vessels are injured or diseased may be quite difficult. Moret et al have proposed an endovascular technique based on retrograde transcirculation approach through communicating vessels.

Methods We report on the first Brazilian experience with retrograde endovascular approach, to the best of our knowledge.

Results The two cases illustrate difficult anterograde approach techniques to treat basilar apex aneurysms. In the first case, tortuosity and angulation of both vertebral arteries associated to stenosis did not allow an anterograde approach. In the second case, after a SAH of a basilar apex aneurysm treated more than a decade ago with bilateral vertebral artery trapping, the patient underwent a retrograde approach.

\section{Keywords \\ - endovascular \\ - aneurysm \\ - treatment}

\section{Resumo}

\section{Palavras-chave \\ - endovascular \\ - aneurisma \\ - tratamento}

Conclusion For this approach, follow-up data are still lacking and complications are usually more common than in anterograde approach. Nevertheless, in select cases, it may be applied by experienced hands with acceptable risks when no other treatment option (surgical or endovascular) is available.

Introdução O tratamento de lesões específicas quando vasos são danificados, ficam doentes ou inacessíveis pode se tornar bastante difícil. Moret et al propuseram uma técnica endovascular baseada no acesso retrógrado pelos vasos comunicantes.

Métodos Primeira experiência Brasileira em acesso endovascular retrógrado, segundo os autores do presente estudo.

Resultados Os dois casos demonstram técnicas de difícil acesso anterógrado para tratar aneurismas do ápice basilar. No primeiro caso, a tortuosidade e a angulação de ambas as artérias vertebrais associadas à estenose não permitiram acesso anterógrado. No segundo caso, após hemorragia subaracnóidea do aneurisma de ápice basilar
\end{abstract}

received

August 12, 2015

accepted

October 8, 2015

published online

December 14, 2015
Copyright $(2017$ by Thieme Revinter

Publicações Ltda, Rio de Janeiro, Brazil
License terms

(c) (i) $\ominus \circledast$ 10.1055/s-0035-1570116. ISSN 0103-5355. 
tratado há mais de uma década com oclusão de artéria vertebral bilateral, realizou-se um acesso retrógrado.

Conclusão Para este acesso, dados subsequentes ainda são necessários, e complicações ainda são mais comuns que em acesso anterógrado. Mesmo assim, pode ser aplicado em casos específicos com riscos aceitáveis e em mãos experientes, quando nenhum outro tratamento (cirúrgico ou endovascular) seja possível.

\section{Introduction}

Although endovascular treatment has progressively advanced over the last years, the treatment of target lesions when parent vessels are injured, diseased, or tortuous may be quite difficult. In this sense, Moret et $\mathrm{al}^{1}$ have proposed an endovascular technique based on the retrograde transcirculation approach through communicating vessels. ${ }^{2,3}$ It involves the navigation of a catheter, balloon, or stent delivery device either from one arterial side to the other or from the anterior to the posterior circulation. ${ }^{2-5}$

We report two cases treated with the retrograde endovascular approach, which are the first Brazilian experiences, to the best of our knowledge.

\section{Case 1}

A 67-year-old white woman presented for neuroradiological investigation of a 6-month history of progressively worsening pulsatile headache. Her past medical history was positive for smoking, diabetes mellitus, and arterial hypertension. She denied any family history of intracranial aneurysms. Her clinical and neurological examinations were unremarkable. Magnetic resonance imaging (MRI) of the brain revealed a saccular aneurysm of $\sim 6 \mathrm{~mm}$ in the basilar artery apex. She was then forwarded for a cerebral angiogram ( - Fig. 1), which disclosed a solitary saccular aneurysm in the basilar apex.

Due to the size and location of aneurysm, associated with other risk factors like smoking and hypertension, we proposed

A

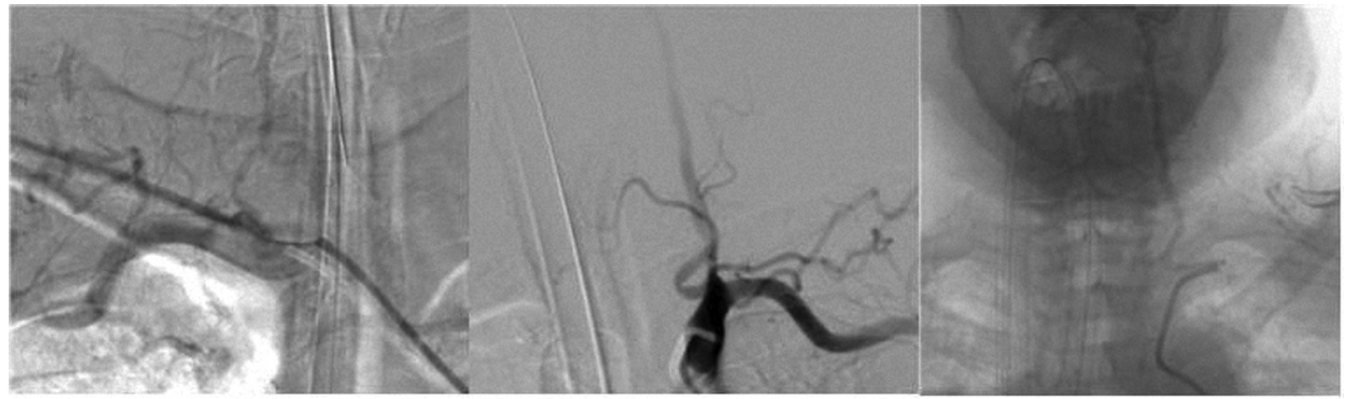

B
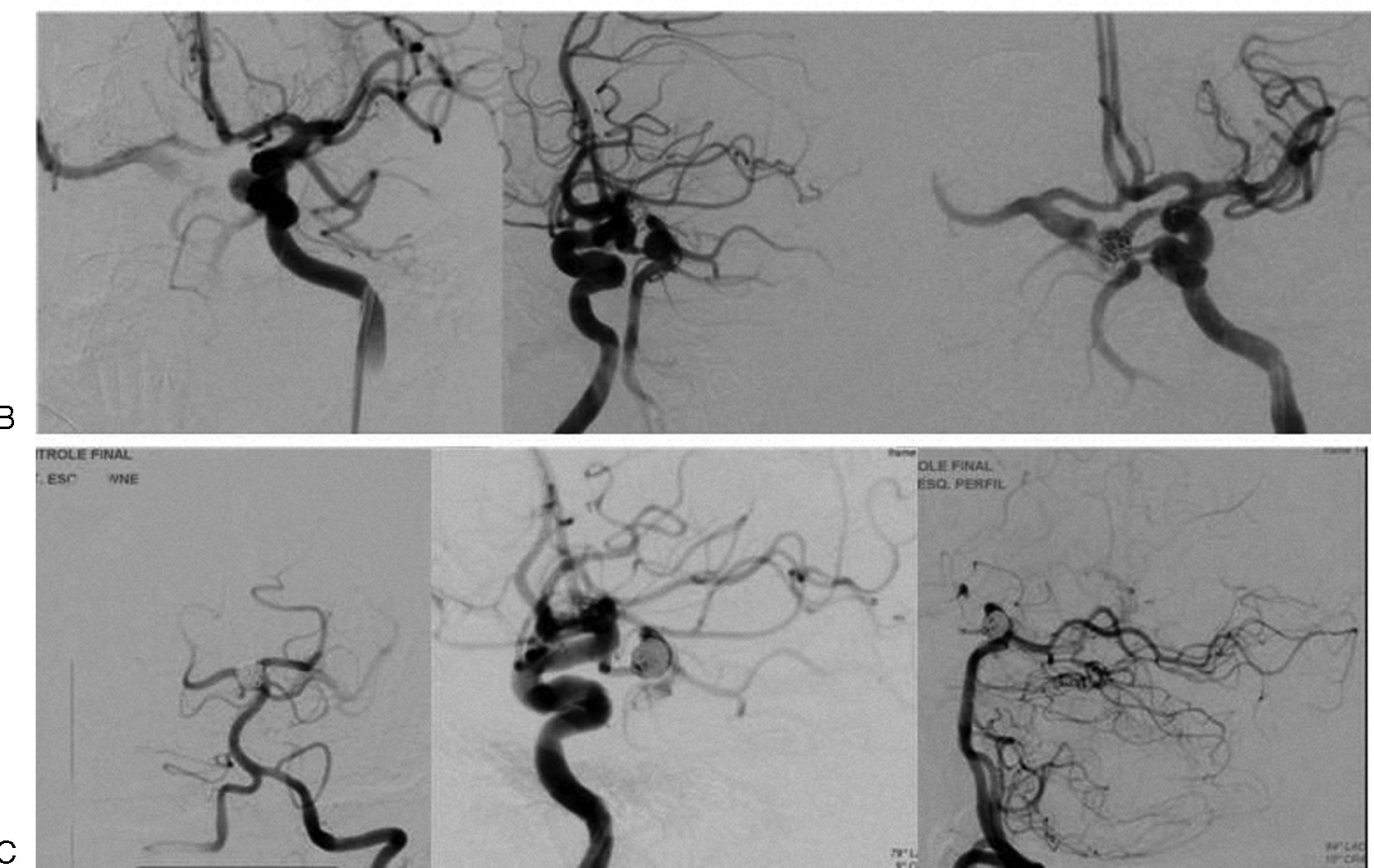

Fig. 1 (A) Angiogram of patient number 1, which disclosed accentuated angulation of tortuosity of vertebral arteries. (B) Retrograde approach revealing basilar apex aneurysm. (C) Embolization performed with coils through retrograde approach. 

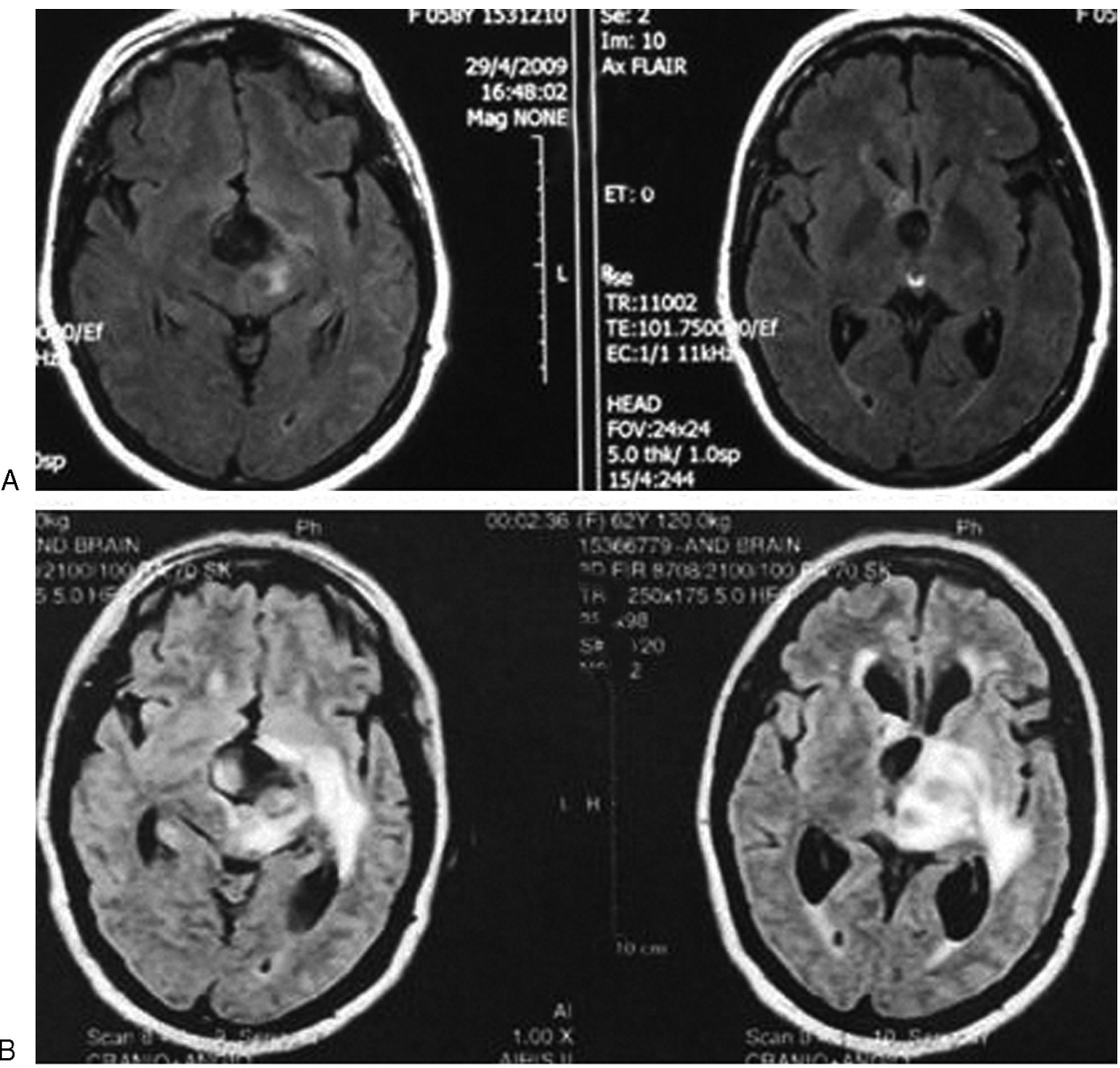

B

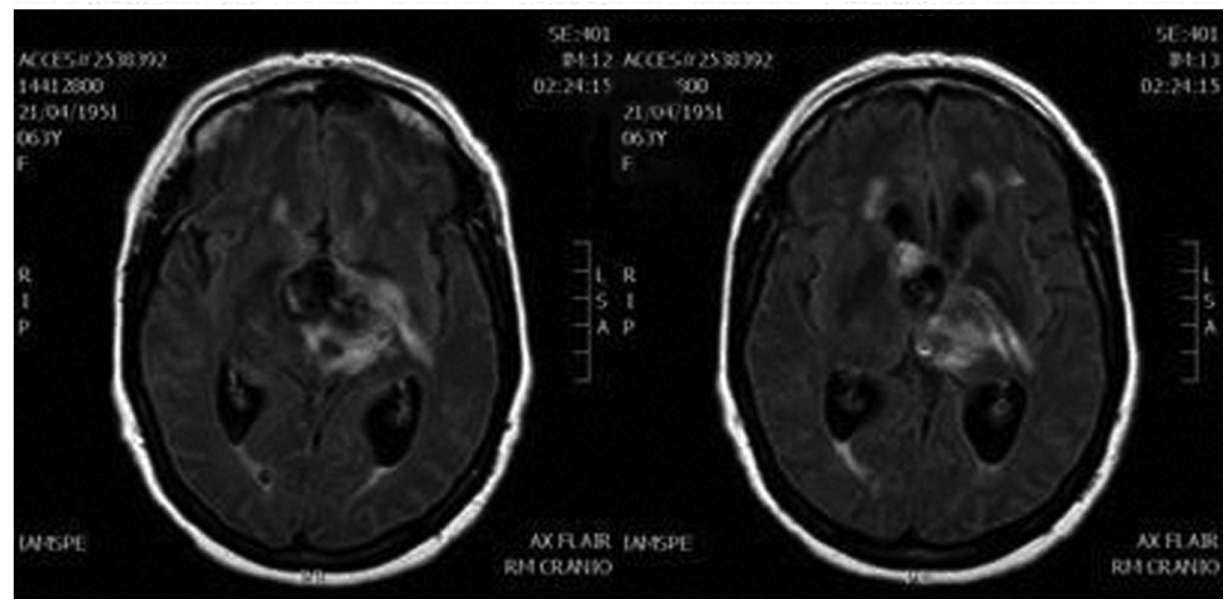

Fig. 2 MRI of patient number 2 in three moments: (A) after aneurismal diagnosis; (B) after trapping of vertebral arteries and worsening of symptoms, revealing perianeurysmal edema in FLAIR; (C) in immediate post retrograde approach embolization, showing decrease in perianeurysmal edema.

aneurismal treatment by endovascular approach. During the endovascular approach, it was very difficult to catheterize both vertebral arteries due to extreme tortuosity and segmental stenosis ( - Fig. 1A). When we achieved catheterization of the left vertebral artery, the endovascular catheter interrupted the blood flow and, thus, we aborted the procedure. Although we could have attempted angioplasty and stenting of proximal vertebral artery to allow catheter progression, such a procedure usually entails a high probability of late restenosis and, consequently, unsuccessful stenting.
Therefore, the endovascular team catheterized the left carotid artery with a Simmons catheter to approach aneurysmal sac, reaching the aneurysm by a retrograde transcirculation approach (-Fig. 1B). Despite being a more complex and technically difficult procedure given that anterior circulation was also affected by atherosclerotic plaques, we performed embolization cautiously with slow progression of catheter and gentle manipulation, which resulted in success without complications (-Fig. 1C). The patient recovered well and was discharged without deficits. 


\section{Case 2}

A 62-year-old white woman presented with progressive headache for two years in 2001. Her past medical history was negative for smoking, alcohol intake, and medication use. She mentioned having diabetes mellitus and arterial hypertension. Moreover, she denied any family history of intracranial aneurysms and her clinical and neurological examinations were unremarkable. Brain MRI showed a saccular aneurysm of $\sim 20 \mathrm{~mm}$ at the basilar apex ( - Fig. 2A). At the time, an angiogram revealed a giant basilar artery apex aneurysm ( - Fig. 3A). The patient was forwarded for aneurysmal treatment, but missed followup.

One year later, she was admitted to our emergency room with subarachnoid hemorrhage (SAH) Fisher IV and Hunt Hess IV. At the time, we proposed aneurysmal treatment by endovascular approach. We performed an endovascular trapping of both vertebral arteries with coils (-Fig. 3B). The patient was discharged with a GOS of 4 and recovered well, maintaining annual follow-up. In 2005, the follow-up angiogram evidenced a partially thrombosed giant basilar apex aneurysm filling from anterior circulation (-Fig. 3C). Nonetheless, the patient remained asymptomatic.
Six months prior to this present study conclusion, she had begun complaining of pulsatile headache and gait disturbance. Her clinical and neurological examinations revealed a right-sided complete hemiparesis (Grade IV). Brain MRI showed a partially thrombosed aneurysm increasing in size and with remarkable perineurysmal edema ( $\mathbf{- F i g . ~ 2 B ) . ~ A n o t h e r ~ a n g i o g r a m ~ r e v e a l e d ~ a ~}$ basilar artery apex aneurysm (-Fig. 3D). At this point, since the aneurysm was increasing and the patient was symptomatic, a decision was made to perform treatment.

During the endovascular approach, given that both vertebral arteries were trapped, it was necessary to reach both carotid arteries and perform a retrograde treatment ( - Fig. 3D). Both posterior communicating arteries were patent and large, allowing for embolization of aneurysm with coils and posterior positioning of right P1 to left P1 with Solitaire stent without complications (-Fig. 3D). The patient recovered well and was discharged without new deficits. Immediate post-procedure MRI revealed decreased perianeurysmal edema ( - Fig. 2C).

\section{Discussion}

Both cases discussed here illustrated difficult anterograde approach techniques to treat basilar apex aneurysms. In the first case, tortuosity and angulation of both vertebral arteries
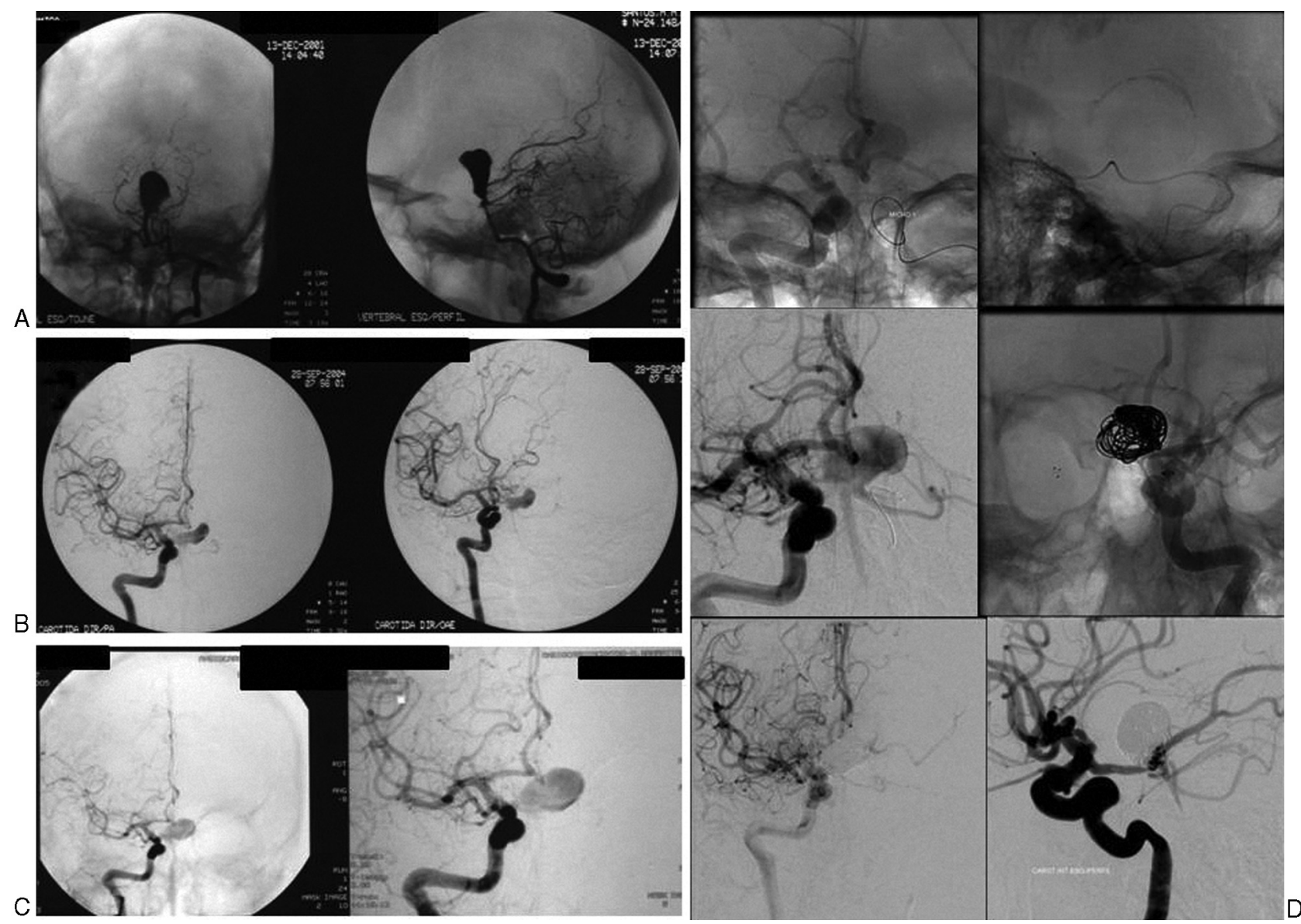

Fig. 3 Angiogram of patient number 2: (A) after basilar apex aneurysm diagnose and before vertebral trapping; (B) after vertebral trapping, revealing retrograde filling of aneurysm with partially thrombosed component; (C) follow-up angiogram, disclosing increasing size of aneurysm; (D) at the onset of symptoms and during retrograde approach embolization with stent delivery. 
associated with stenosis did not allow an anterograde approach. In the second case, after a SAH of a basilar apex aneurysm treated more than a decade ago with bilateral endovascular vertebral artery trapping, the approach used was the retrograde. Both cases recovered well without complications.

Transcirculation catheterization, also known as the retrograde approach, involves the navigation of a catheter, a balloon, or a stent delivery device either from one arterial side to the other, or from the anterior to the posterior circulation. ${ }^{1-5}$ The rationale behind it lies on the existence of patent collateral circulation. Thus, adequate patency is required either for the posterior (PComA) and anterior communicating arteries (ACOA) or for both vertebral arteries (VAs).

In all cases, a special set must be ready to perform retrograde approach. The most important difference is that, once target lesions are reached against the bloodstream, two proximal arteries must be punctured: one to manipulate the catheter and the other to provide intravenous contrast and guide retrograde navigation. In our first case, retrograde approach was performed through carotid artery and contrast was injected by vertebral artery. In the second case, we used one carotid for the retrograde approach and the other for contrast injection.

Then, navigation may be divided in two parts, one along the bloodstream and the other against bloodstream. While the first is a common approach, the latter must be conducted with slow progression of the catheter and gentle manipulation, to avoid vessel injury. We prefer using Simmons catheters, which allows gentle movements. Catheter size should not be different from those applied in anterograde approaches. Smaller sizes increase difficulty of catheter progression and larger sizes, although easier to navigate, may increase risks for vascular insufficiency in vessels already injured and overloaded.

When reaching the target lesion, it is necessary to strengthen precautions during treatment, since the catheter may shift during coiling and the coils may migrate distally.

Such a technique is particularly effective for treating widenecked basilar apex, ACoA aneurysms, aneurysms involving a fetal PComA, superior cerebellar artery (SCA) aneurysms, intracranial vertebral artery (V4 segment) aneurysms, carotid terminus aneurysms, and posterior inferior cerebellar artery (PICA) aneurysms. ${ }^{1-3}$ Simultaneous angiography through the two target brachiocephalic vessels delineates adequately the route of catheterization. Transcirculation navigation of a catheter, a balloon, or a stent-deployment device facilitates primary coiling of the aneurysm. The technique described was developed to allow optimal treatment of aneurysms that otherwise were difficult or impossible to access. ${ }^{2-5}$

Moret et $\mathrm{al}^{1}$ have pioneered the technique and reached the result of completely or near completely coiled aneurysms in all 12 cases described. ${ }^{1}$ Two complications occurred as a result of treatment. One patient developed status epilepticus and the second complication occurred in a patient with an ICA terminus aneurysm who developed a thrombus within the M1 arterial segment, which was treated with thrombolysis. ${ }^{1}$

Moret et al emphasized the role of three-dimensional angiography for the success of transcirculation catheterization. ${ }^{1}$ Not only can three-dimensional angiography demonstrate the optimal working angle for parent vessel preservation during coiling, but it can also be used to optimize visualization of the transcirculation route. ${ }^{1}$

Albuquerque et $\mathrm{al}^{2}$ stated that these techniques are invaluable in the treatment of complex cerebral aneurysms. Their use, however, should be reserved for patients for whom the risks of leaving their aneurysms untreated are high. ${ }^{2}$ The comparative morbidity and mortality associated with a conventional surgical approach should also be weighed against the risks of these technically challenging endovascular approaches. Their series was the largest number of patients treated through transcirculation routes. ${ }^{2}$

Other reports have documented the transcirculation deployment of stents for the treatment basilar apex aneurysms, ICA terminus aneurysms, and ACoA aneurysms. ${ }^{3-5}$

\section{Conclusions}

Long-term follow-up in patients treated with this technique is not yet available. Additionally, complications are usually more common than those in anterograde approach. ${ }^{1,2} \mathrm{Nev}-$ ertheless, in select cases with better indication for endovascular procedures (such as basilar apex aneurysms), it may be applied with acceptable risks in experienced hands when no other treatment option (surgical or endovascular) is available.

\section{Conflicts of Interest}

The authors declare no conflicts of interest.

\section{References}

1 Moret J, Ross IB, Weill A, Piotin M. The retrograde approach: a consideration for the endovascular treatment of aneurysms. AJNR Am J Neuroradiol 2000;21(2):262-268

2 Albuquerque FC, Gonzalez LF, Hu YC, Newman CB, McDougall CG. Transcirculation endovascular treatment of complex cerebral aneurysms: technical considerations and preliminary results. Neurosurgery 2011;68(3):820-829, discussion 829830

3 Caplan J, Huang J, Tamargo R, Radvany M. E-032 retrograde stentassisted coil embolization of posterior communicating artery aneurysms. J Neurointerv Surg. 2014;6(Suppl 1):A52

4 Cho YD, Kim KM, Lee WJ, Kang HS, Kim JE, Han MH. Retrograde stenting through the posterior cerebral artery in coil embolization of the posterior communicating artery aneurysm. Neuroradiology 2013;55(6):733-739

5 Heye S, Stracke CP, Nordmeyer H, Heddier M, Stauder M, Chapot R. Retrograde access to the posterior inferior cerebellar artery in balloon-assisted coiling of posterior inferior cerebellar artery aneurysms. J Neurointerv Surg 2015;7(11):824-828 